\title{
Multiarterial grafting: Why is it so hard to convince the masses of the benefits?
}

Michael P. Vallely, MBBS, PhD, FRACS, ${ }^{\text {a }}$ Fabio Ramponi, MD, FEBVS, ${ }^{b}$

Michael Seco, BMedSc, MBBS, PhD, ${ }^{b}$ and Alistair Royse, MBBS, MD, FRACS, FCSANZ

We will go to the moon in this decade and do the other things, not because they are easy, but because they are hard, because that goal will serve to organize and measure the best of our energies and skills.

\section{—President John F. Kennedy, 1962}

Perplexingly, the debate of single arterial grafting (SAG) versus multiple arterial grafting (MAG) and total arterial grafting (TAG) has continued. This is despite strong historical and contemporary case series, registry data, and meta-analyses that have demonstrated the benefits of bilateral internal thoracic artery and MAG strategies..$^{2-9}$

In a recent editorial, Taggart ${ }^{10}$ (a dedicated anaortic MAG surgeon) highlighted 3 main reasons he believed that the wider surgical community has been reluctant to move away from a single left internal thoracic artery (LITA)-to-left anterior descending (LAD) and vein grafts to other targets:

1. Lack of supportive evidence from randomized trials to support a change in practice

2. Potential for an increased risk of morbidity and mortality (in particular, deep sternal wound infection)

3. Perceived increased technical complexity of using MAG strategies

However, we believe these reasons can be countered by the current evidence available.

First, the results of the largest randomized study comparing bilateral internal thoracic artery (BITA) to single internal thoracic artery (SITA), the arterial revascularization trial (ART), ${ }^{11}$ have indicated that using an intentionto-treat basis, the ART did not demonstrate a difference in death or a composite of death, myocardial infarction, or stroke at 10 years. Although this appears to support the SAG strategy, almost $40 \%$ of participants had actually received a different therapy to the one proposed in the trial, including a $14 \%$ crossover rate from BITA to SITA. Also,

From the a Division of Cardiac Surgery, The Ohio State University Wexner Medical Center, Columbus, Ohio; 'bydney Medical School, The University of Sydney, Sydney, New South Wales, Australia; and ${ }^{\mathrm{c} D e p a r t m e n t ~ o f ~ C a r d i o t h o r a c i c ~ S u r g e r y, ~}$ The Royal Melbourne Hospital, University of Melbourne, Melbourne, Victoria, Australia.

Received for publication March 6, 2020; revisions received April 18, 2020; accepted for publication April 25, 2020; available ahead of print June 24, 2020.

Address for reprints: Michael P. Vallely, MBBS, PhD, FRACS, Division of Cardiac Surgery, The Ohio State University, N-805 Doan Hall, 410 West 10th Ave, Columbus, OH 43210 (E-mail: michael.vallely@osumc.edu).

J Thorac Cardiovasc Surg 2021;161:1832-6

$0022-5223 / \$ 36.00$

Copyright (C) 2020 by The American Association for Thoracic Surgery

https://doi.org/10.1016/j.jtcvs.2020.04.185

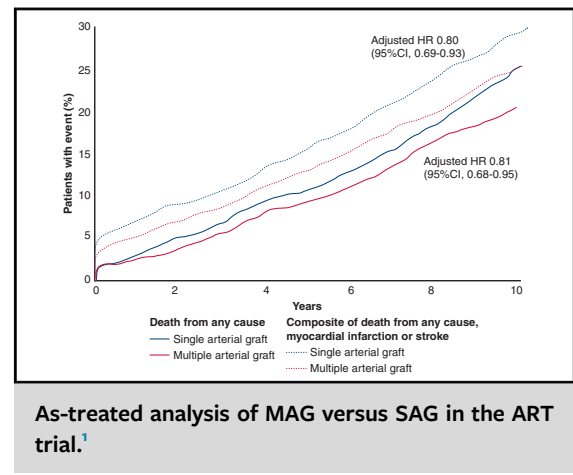

CENTRAL MESSAGE

Multiple arterial grafting strate-

gies are supported by an

increasing amount of robust ev-

idence and are safely applicable

to most patients after adequate

subspecialized training.

This Invited Expert Opinion provides a perspective on the following paper: J Am Coll Cardiol. 2019;74(18):2238-2248. https://doi.org/10.1016/j.jacc. 2019.08.1043.

See Commentary on page 1837. 


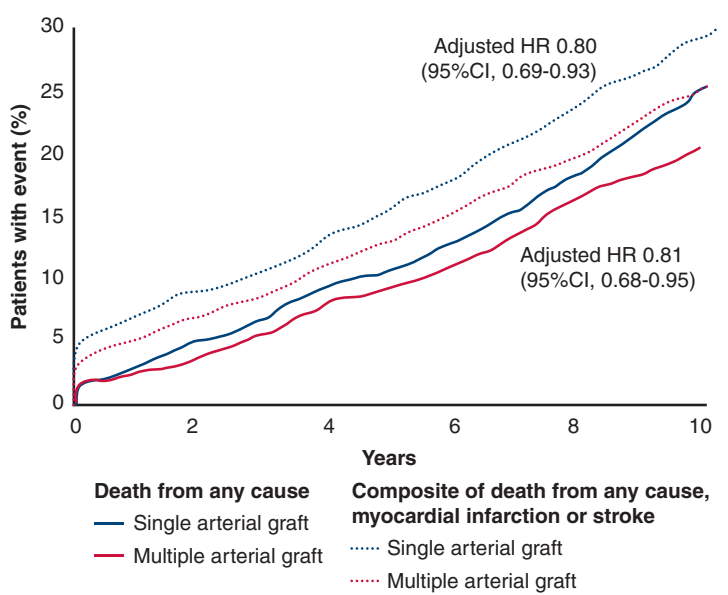

A

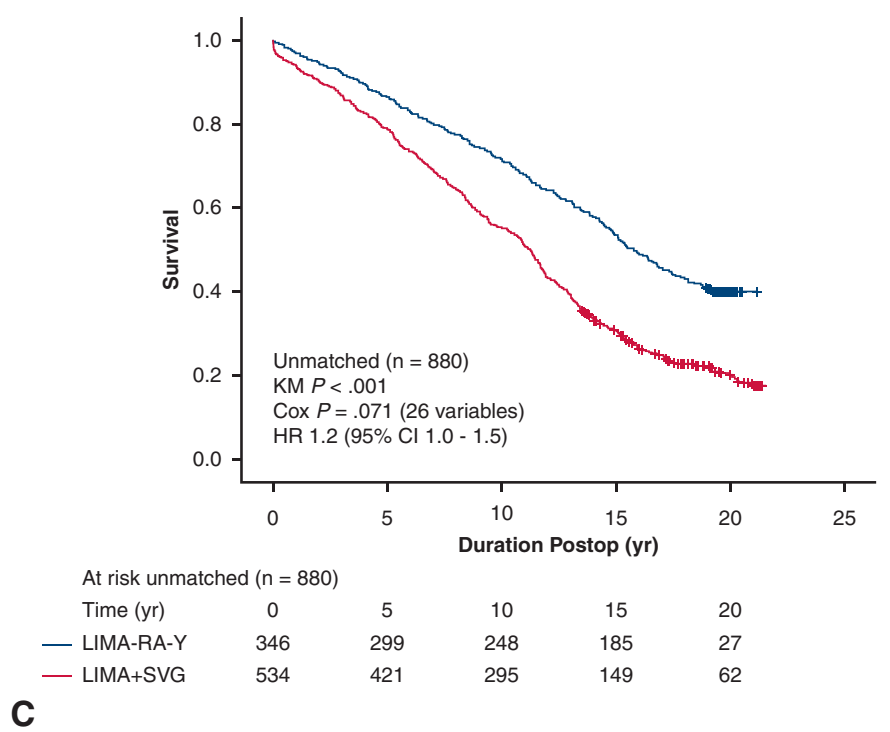

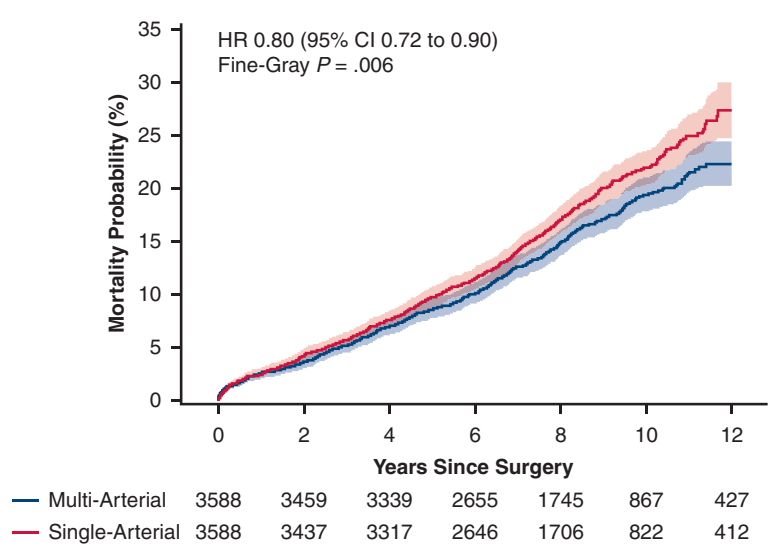

B

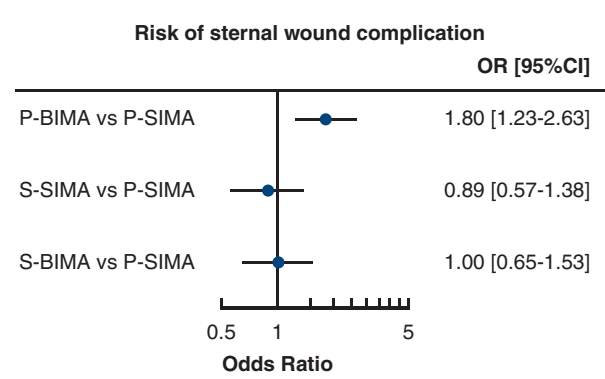

FIGURE 1. A, As-treated analysis of multiple arterial grafting (MAG) versus single arterial grafting (SAG) in the arterial revascularization trial. ${ }^{1}$ $\mathrm{B}$, Ten-year mortality of MAG versus SAG from a large registry-based series. ${ }^{12} \mathrm{C}$, Survival at 21 years of left internal thoracic artery (LITA)- radial artery $(R A)$ Y-graft versus LITA (originally left internal mammary artery) plus saphenous vein graft $(S V G) .{ }^{13} \mathrm{D}$, Effect of skeletonization on sternal wound infection risk during bilateral internal thoracic artery (BITA) and single internal thoracic artery (SITA) grafting. ${ }^{14} \mathrm{HR}$, Hazard ratio; $C I$, confidence interval; $K M$, Kaplan-Meier; LIMA, left internal mammary artery; OR, odds ratio; BIMA, bilateral internal mammary arteries; SIMA, single internal mammary artery.

crossover rate $(\leq 100 \%)$ and that the surgeons who had performed more operations in the trial appeared to have had lower crossover rates. This is not a new phenomenon-randomized trials in cardiac surgery have previously been hampered by (a lack of) surgical experience. ${ }^{15,16}$ Should a minimum level of experience or demonstration of proficiency be required to participate in these trials or should alterative trial designs be tested ${ }^{17}$ (eg, expertise-based randomization)? This presents a detractor for the surgical community relying solely on the existing randomized data to support a change in practice. A second large trial (ROMA [randomization of single vs multiple arterial grafts]), comparing a SITA plus a vein graft versus MAGs (a second ITA or RA to graft the main target vessel of the lateral wall), is currently underway. ${ }^{18}$ The results are expected in 2025.

Significant observational data are also available to support the use of MAG strategies. Most recently, a large study by Chikwe and colleagues ${ }^{12}$ compared SAG and MAG using propensity-score matching and patients from the New Jersey State Open Heart Registry $(n=26,124$; 3588 matched pairs). The findings were compelling, with the use of MAG associated with lower 10-year mortality $(15.1 \%$ vs $17.3 \% ; P=.01$; Figure $1, B)$, myocardial infarction (HR, $0.81 ; \quad 95 \% \quad \mathrm{CI}, \quad 0.69-0.95)$, and reintervention rate (HR, $0.81 ; 95 \% \mathrm{CI}, 0.67-0.99)$. Another 
recent propensity-matched study by Royse and colleagues ${ }^{19}$ demonstrated reduced survival with the use of any saphenous vein graft (SVG). These findings are consistent with other historical and contemporary reports, ${ }^{1-9,13}$ including a large retrospective review from the Cleveland Clinic, which showed a significant long-term survival advantage when the second ITA was deployed to a non-LAD coronary artery supplying an important amount of myocardium (determined by the vessel length, $>75 \%$ terminal reach to the cardiac apex). ${ }^{20}$

Finally, a recent meta-analysis by Gaudino and colleagues $^{21}$ compared drug-eluting stents versus coronary artery bypass (MAG and SAG) for the primary outcome of long-term mortality and the secondary endpoints of operative mortality, perioperative stroke, and follow-up repeat revascularization. Overall, a MAG strategy was ranked as the best treatment for both primary and all secondary endpoints.

The right internal thoracic artery (RITA) is not the only second arterial graft. The RA could have some advantages over the RITA, including that the left RA can be taken simultaneously with the LITA and eliminates any increased risk of sternal wound infection related to BITA grafting. A recent network meta-analysis by Gaudino and colleagues ${ }^{22}$ simultaneously compared the RA, RITA, and SVG as the second conduit. The use of an SVG resulted in greater long-term mortality than the RA (incidence rate ratio, 1.23 ; 95\% CI, 1.12-1.34) and RITA (incidence rate ratio, 1.26 ; $95 \%$ CI, 1.17-1.35). Additionally, no difference was found in mortality or major morbidity between the RITA and RA. The long-term superiority of a LITA/RA Y-graft configuration compared with a SAG strategy has also been reported by Royse and colleagues. ${ }^{13}$ Using propensity-score matching, the investigators demonstrated a survival advantage at $\leq 21$ years for the LITA/RA total arterial strategy (Cox proportional HR, 1.3; 95\% CI, 1.0-1.6; $P=.038$; Figure 1, $C$ ).

The current European Guidelines on Myocardial Revascularization advocate a MAG strategy for all patients with a life expectancy $>5$ years. ${ }^{23}$ One could argue that patients with a life expectancy $<5$ years should not be offered coronary artery bypass grafting (CABG) if percutaneous intervention is feasible and that all remaining patients should receive MAG. The European guidelines have also advocated an "aortic no-touch" (anaortic) approach for all patients at high risk of stroke or those with ascending aortic disease-which will include most, if not all, elderly patients. Anaortic surgery uses ITA inflow to allow for construction of composite grafts that will facilitate complete revascularization; thus, anaortic surgery lends itself well to a MAG approach. $^{24}$
Second, the argument that the use of BITA will be associated with increased deep sternal wound infection has also not been borne out in large case series ${ }^{25,26}$ nor from a post hoc analysis of the $\mathrm{ART}^{14}$ when a fully skeletonized technique has been used. The latter study demonstrated the importance of skeletonization, which minimizes surgical trauma and maintains the sternal blood supply and venous drainage, by demonstrating that pedicled BITAs resulted in increased risk but not when skeletonized compared with a pedicled SITA (Figure 1, D).

A pragmatic approach to BITA use should be considered for morbidly obese and/or patients with poorly controlled diabetes. However, this should not preclude these patients from receiving MAG or, indeed, TAG. The use of a LITA/ RA composite graft will achieve complete revascularization in most patients with a normal length arm and anything less than gross cardiomegaly. This strategy also lends itself to an anaortic approach, which has been shown to significantly reduce all-cause mortality and neurologic and other morbidity. ${ }^{27}$

We believe argue that it is "surgical inertia" that accounts for the vast majority of surgeons not adding a BITA graft to their patients' grafting strategy. The harvesting of a BITA must be performed sequentially, in contrast to an SVG or a RA, which can be harvested simultaneously. It would seem that the argument of increased sternal wound complications might, in part, explain the avoidance by surgeons to extend the length and complexity of an operation that otherwise might result in prolongation of life expectancy and freedom from morbidity. In reality, once surgeons have become accustomed to the refined technical skills required and free themselves from the LITA-to-vein mindset, the additional deployment of a second skeletonized ITA as a composite graft (tandem or Y) will usually not prolong the overall surgical time for $>30$ minutes (with no effects on the bypass or cross-clamp time). We would argue that this extra time is a valuable investment to allow the crafting of a more refined treatment regimen.

The compelling evidence of the benefits of the RA, ${ }^{28}$ and the potential equivalence to the RITA as a second conduit, ${ }^{22}$ also counter the concern regarding an increased risk of sternal wound infection from RITA harvest. The harvesting of the RA is straightforward and simple.

Finally, the argument of "increased complexity" as a reason to continue with SAG is perplexing. The first LITA (originally left internal mammary artery) to the LAD was performed in the $1960 \mathrm{~s},{ }^{29,30}$ with the landmark 1969 series by Favaloro $^{31}$ of SVG aortocoronary grafting, establishing $\mathrm{CABG}$ as a viable therapy for coronary artery disease. Data from the Cleveland Clinic on the benefits of 
SITA in the 1980s established the LITA as the mainstay of CABG. ${ }^{32}$ Data from the Cleveland Clinic and from Gabriele D'Annunzio University in Chieti reported by Calafiore and colleagues $^{33}$ have also highlighted the benefits of BITA over SITA grafting in the 1990s.

Coronary artery disease is the number one cause of death in the world, ${ }^{34}$ and coronary artery surgery has remained the most common cardiac surgical procedure performed by adult cardiac surgical units and (usually) by most surgeons performing adult cardiac surgery. It has also remained a superior intervention to percutaneous coronary intervention for multivessel disease, ${ }^{35,36}$ which contrasts with recent data on other common surgical procedures such as aortic valve replacement. However, CABG often does not receive the attention that it deserves. This has been evident at local levels, with surgeons and units seeing CABG as a commodity item, and at the wider level, with industry and conference attention given to structural heart, aortic surgery, and other aspects of cardiac surgery, exceeding that of CABG.

The paradigm shift must start from the origin of surgical training. Cardiothoracic surgery is a technically demanding surgical specialty, and advanced coronary surgery requires a versatile mindset combined with impeccable technical skills and endless dedication. To facilitate the transition to more technically demanding strategies, cardiothoracic surgeons in training should familiarize themselves from the outset with time-efficient skeletonized harvesting, manipulation of arterial conduits, construction of composite grafts, and quality assessment using transient time flowmetry.

Mirroring the transition to minimally invasive valve surgery, advanced coronary training courses and proctoring by MAG experts should be available to surgeons willing to increase their skills and develop an advanced coronary program, including MAG, TAG, and anaortic surgery. ${ }^{37}$ Surgeons such as Dr Teresa Kieser have mastered the skeletonized technique and her lectures are well illustrated with excellent technical videos, all available online.

National society quality bundles should capture the rate of MAG, TAG, and/or anaortic strategies. Also, contraindications to their use should be documented, especially for young, nondiabetic, nonobese patients, and when aortic calcification is present.

Mack and Taggart $^{38}$ have advocated for CABG to become a subspecialty interest; however, the sheer volume of patients requiring CABG could make this an unwieldy solution. We would argue that a stepwise approach to MAG with an increased adoption of the RA and then the RITA as a graft to allow surgeons to familiarize themselves would be a good place to start. Adding a second ITA or an $\mathrm{RA}$ is not technically onerous.

\section{Conflict of Interest Statement}

The authors reported no conflicts of interest.

The Journal policy requires editors and reviewers to disclose conflicts of interest and to decline handling or reviewing manuscripts for which they may have a conflict of interest. The editors and reviewers of this article have no conflicts of interest.

\section{References}

1. Gaudino M, Bakaeen FG, Benedetto U, Di Franco A, Fremes S, Glineur D, et al. Arterial grafts for coronary bypass: a critical review after the publication of ART and RADIAL. Circulation. 2019;140:1273-84.

2. Lytle BW, Cosgrove DM, Saltus GL, Taylor PC, Loop FD. Multivessel coronary revascularization without saphenous vein: long-term results of bilateral internal mammary artery grafting. Ann Thorac Surg. 1983;36:540-7.

3. Lytle BW, Blackstone EH, Loop FD, Houghtaling PL, Arnold JH, Akhrass R, et al. Two internal thoracic artery grafts are better than one. J Thorac Cardiovasc Surg. 1999;117:855-72.

4. Taggart DP, D'Amico R, Altman DG. Effect of arterial revascularisation on survival: a systematic review of studies comparing bilateral and single internal mammary arteries. Lancet. 2001;358:870-5.

5. Yi G, Shine B, Rehman SM, Altman DG, Taggart DP. Effect of bilateral internal mammary artery grafts on long-term survival: a meta-analysis approach. Circulation. 2014;130:539-45.

6. Iribarne A, Schmoker JD, Malenka DJ, Leavitt BJ, McCullough JN, Weldner PW, et al. Does use of bilateral internal mammary artery grafting reduce long-term risk of repeat coronary revascularization? A multicenter analysis. Circulation. 2017; 136:1676-85

7. Takagi H, Goto SN, Watanabe T, Mizuno Y, Kawai N, Umemoto T. A metaanalysis of adjusted hazard ratios from 20 observational studies of bilateral versus single internal thoracic artery coronary artery bypass grafting. J Thorac Cardiovasc Surg. 2014;148:1282-90.

8. Rocha RV, Tam DY, Karkhanis R, Wang X, Austin PC, Ko DT, et al. Long-term outcomes associated with total arterial revascularization vs non-total arterial revascularization. JAMA Cardiol. 2020;5:1-8.

9. Rocha RV, Tam DY, Karkhanis R, Nedadur R, Fang J, Tu JV, et al. Multiple arterial grafting is associated with better outcomes for coronary artery bypass grafting patients. Circulation. 2018;138:2081-90.

10. Taggart DP. The role of multiple arterial grafts in CABG: all roads lead to ROMA [editorial]. J Am Coll Cardiol. 2019;74:2249.

11. Taggart DP, Benedetto U, Gerry S, Altman DG, Gray AM, Lees B, et al. Bilateral versus single internal-thoracic-artery grafts at 10 years. N Engl J Med. 2019;380: 437-46.

12. Chikwe J, Sun E, Hannan EL, Itagaki S, Lee T, Adams DH, et al. Outcomes of second arterial conduits in patients undergoing multivessel coronary artery bypass graft surgery. J Am Coll Cardiol. 2019;74:2238-48.

13. Royse AG, Brennan AP, Ou-Young J, Pawanis Z, Canty DJ, Royse CF. 21-year survival of left internal mammary artery-radial artery-Y graft. J Am Coll Cardiol. 2018;72:1332-40.

14. Benedetto U, Altman DG, Gerry S, Gray A, Lees B, Pawlaczyk R, et al. Pedicled and skeletonized single and bilateral internal thoracic artery grafts and the incidence of sternal wound complications: insights from the arterial revascularization trial. J Thorac Cardiovasc Surg. 2016;152:270-6.

15. Shroyer AL, Grover FL, Hattler B, Collins JF, McDonald GO, Kozora E, et al On-pump versus off-pump coronary-artery bypass surgery. $N$ Engl J Med. 2009;361:1827-37

16. McCulloch P, Taylor I, Sasako M, Lovett B, Griffin D. Randomised trials in surgery: problems and possible solutions. BMJ. 2002;324:1448-51.

17. Devereaux PJ, Bhandari M, Clarke M, Montori VM, Cook DJ, Yusuf S, et al Need for expertise based randomised controlled trials. BMJ. 2005;330:88.

18. Gaudino M, Alexander JH, Bakaeen FG, Ballman K, Barili F, Calafiore AM et al. Randomized comparison of the clinical outcome of single versus multiple arterial grafts: the ROMA trial-rationale and study protocol. Eur J Cardiothorac Surg. 2017;52:1031-40.

19. Royse A, Pawanis Z, Canty D, Ou-Young J, Eccleston D, Ajani A, et al. The effect on survival from the use of a saphenous vein graft during coronary bypass surgery: a large cohort study. Eur J Cardiothorac Surg. 2018;54:1093-100. 
20. Bakaeen FG, Ravichandren K, Blackstone EH, Houghtaling PL, Soltesz EG, Johnston DR, et al. Coronary artery target selection and survival after bilateral internal thoracic artery grafting. J Am Coll Cardiol. 2020;75:258-68.

21. Gaudino M, Rahouma M, Abouarab A, Tam DY, Di Franco A, Leonard J, et al. Meta-analysis comparing outcomes of drug eluting stents versus single and multiarterial coronary artery bypass grafting. Am J Cardiol. 2018;122: 2018-25.

22. Gaudino M, Lorusso R, Rahouma M, Abouarab A, Tam DY, Spadaccio C, et al. Radial artery versus right internal thoracic artery versus saphenous vein as the second conduit for coronary artery bypass surgery: a network meta-analysis of clinical outcomes. J Am Heart Assoc. 2019;8:e10839.

23. Neumann FJ, Sousa-Uva M, Ahlsson A, Alfonso F, Banning AP, Benedetto U, et al. 2018 ESC/EACTS guidelines on myocardial revascularization. Eur Heart J. 2019;40:87-165

24. Ramponi F, Seco M, Edelman JB, Sherrah AG, Bannon PG, Brereton RJL, et al. Dual inflow, total-arterial, anaortic, off-pump coronary artery bypass grafting: how to do it. Ann Cardiothorac Surg. 2018;7:552-60.

25. Zhu YY, Seco M, Harris SR, Koullouros M, Ramponi F, Wilson M, et al. Bilateral versus single internal mammary artery use in coronary artery bypass grafting: a propensity matched analysis. Heart Lung Circ. 2019;28:807-13.

26. Calafiore AM, Vitolla G, Iaco AL, Fino C, Di Giammarco G, Marchesani F, et al. Bilateral internal mammary artery grafting: midterm results of pedicled versus skeletonized conduits. Ann Thorac Surg. 1999;67:1637-42.

27. Zhao DF, Edelman JJ, Seco M, Bannon PG, Wilson MK, Byrom MJ, et al. Coronary artery bypass grafting with and without manipulation of the ascending aorta: a network meta-analysis. J Am Coll Cardiol. 2017;69: 924-36.

28. Gaudino M, Benedetto U, Fremes S, Biondi-Zoccai G, Sedrakyan A, Puskas JD, et al. Radial-artery or saphenous-vein grafts in coronary-artery bypass surgery. $N$ Engl J Med. 2018;378:2069-77.
29. Kolessov VI. Mammary artery-coronary artery anastomosis as method of treatment for angina pectoris. J Thorac Cardiovasc Surg. 1967;54:535-44.

30. Goetz RH, Rohman M, Haller JD, Dee R, Rosenak SS. Internal mammarycoronary artery anastomosis: a nonsuture method employing tantalum rings. $J$ Thorac Cardiovasc Surg. 1961;41:378-86.

31. Favaloro RG. Saphenous vein graft in the surgical treatment of coronary artery disease: operative technique. J Thorac Cardiovasc Surg. 1969;58:178-85.

32. Loop FD, Lytle BW, Cosgrove DM, Stewart RW, Goormastic M, Williams GW, et al. Influence of the internal-mammary-artery graft on 10-year survival and other cardiac events. N Engl J Med. 1986;314:1-6.

33. Calafiore AM, Di Giammarco G, Luciani N, Maddestra N, Di Nardo E, Angelini R. Composite arterial conduits for a wider arterial myocardial revascularization. Ann Thorac Surg. 1994;58:185-90.

34. Benjamin EJ, Muntner P, Alonso A, Bittencourt MS, Callaway CW, Carson AP, et al. Heart disease and stroke statistics - 2019 update: a report from the American Heart Association. Circulation. 2019;139:e56-528.

35. Spadaccio C, Benedetto U. Coronary artery bypass grafting (CABG) vs. percutaneous coronary intervention (PCI) in the treatment of multivessel coronary disease: quo vadis? - a review of the evidences on coronary artery disease [editorial]. Ann Cardiothorac Surg. 2018;7:506.

36. Head SJ, Milojevic M, Daemen J, Ahn J-M, Boersma E, Christiansen EH, et al. Mortality after coronary artery bypass grafting versus percutaneous coronary intervention with stenting for coronary artery disease: a pooled analysis of individual patient data. Lancet. 2018;391:939-48.

37. Gaudino M, Chikwe J, Falk V, Lawton JS, Puskas JD, Taggart DP. Transatlantic editorial: the use of multiple arterial grafts for coronary revascularization in Europe and North America. J Thorac Cardiovasc Surg. 2020;159:2254-9.

38. Mack M, Taggart D. Coronary revascularization should be a subspecialty focus in cardiac surgery [editorial]. J Thorac Cardiovasc Surg. 2018; https://doi.org/ 10.1016/j.jtcvs.2018.08.078 [Epub ahead of print]. 